\title{
Activity-Travel Patterns of Non-Workers in the San Francisco Bay Area: An Exploratory Analysis
}

\author{
Rajul Misra and Chandra Bhat \\ Department of Civil Engineering \\ University of Texas at Austin
}

\begin{abstract}
Analysis of activity-travel patterns is an important component of any activity-based transportation planning exercise. Most of the current activity-travel literature focuses on studying the characteristics of workers. In comparison, little emphasis has been placed on studying nonworker activity-travel patterns. This paper presents the results of an exploratory analysis of the activity-travel patterns of non-workers in the San Francisco Bay Area. The attributes of a nonworker's overall activity-travel pattern are examined in terms of three dimensions - number of stops of each activity type, trip chaining, and the temporal sequencing of activities. The paper concludes with a summary of the results and implications for transportation planning and policy analysis.
\end{abstract}




\section{INTRODUCTION}

Travel demand analysis may be based on one of two distinct conceptual paradigms: the trip-based paradigm or the activity-based paradigm.

In the trip-based paradigm, the unit of analysis used is the individual trip and the dimensions of each trip (example, travel mode, destination, etc.) are typically studied independently. The approach assumes that each trip can be analyzed independently without considering the interrelationships that may exist among choices made by individuals for a series of trips. The limitations of the trip-based approach in evaluating traffic congestion-mitigation policies have been well espoused in the transportation literature (for example, see Jones, et. al., 1990). These limitations, along with the growing dissatisfaction of the trip-based paradigm from a behavioral standpoint, have led to the emergence of an activity-based approach to studying travel behavior (see Bhat and Koppelman, 1999, Axhausen and Garling, 1992, and Kurani and Kitamura, 1996 for detailed discussions of this approach).

The activity-based approach views travel as a derived demand; derived from the need to pursue activities distributed over space and time. The conceptual appeal of this approach originates from the realization that the need and desire to participate in activities is more basic than the travel that some of these participations may entail. By placing primary emphasis on activity participation and focusing on sequences or patterns of activity behavior (using the whole day or longer periods of time as the unit of analysis), such an approach can address congestionmanagement issues through an examination of how people modify their activity participations. The shift to an activity-based paradigm has also received an impetus because of the increased information demands placed on travel models by the 1990 Clean Air Act Amendments (CAAAs). Since the activity-based approach adopts a richer, more holistic, approach with detailed representation of the temporal dimension, it is better suited to respond to the new information needs. 
Most existing activity-based travel analysis studies have examined the activity-travel patterns of the working population (for example, see Bhat and Singh, 1998; Mahmassani, et. al., 1997). One of the major motivations for the focus on worker activity choices is the significant effect of commute travel behavior on peak traffic congestion and mobile source emissions. In contrast to the substantial literature on worker activity analysis, relatively little research has been focused on studying the activity-travel behavior of non-workers. However, analysis of the activity-travel behavior of non-workers provides important input for transportation planning. A large proportion of non-workers include children or retired individuals who may have special mobility and accessibility requirements. Another important non-working group comprises homemakers who, while exhibiting high levels of mobility like workers, have rather flexible schedules due to the absence of temporal fixities (unlike commute trips for workers). The underlying factors influencing the travel-related decisions of these non-workers are likely to be quite different from those of workers (see Bianco and Lawson, 1996).

The above discussion motivates the current exploratory analysis of the activity-travel patterns of non-workers in the San Francisco Bay Area. Specifically, the paper focuses on the following stop-making and activity organization attributes characterizing the daily non-worker activity-travel pattern: a) number of out-of-home stops pursued by activity type, b) activity chaining in the daily activity-travel pattern, and c) activity sequencing.

The remainder of this paper is structured as follows. The next section provides an overview of the data source and the sample formation process. Sections 3, 4, and 5 present the analysis results for the three dimensions of the activity-travel pattern analysis described above. Each of these sections begins with a general description of the attributes that characterize that dimension, followed by a more in-depth analysis and estimation results of models representing the effect of household/individual characteristics on each attribute. Section 6 highlights the important findings from the paper, the limitations of this analysis, and provides directions for future work in this area. 


\section{DATA FOR ANALYSIS}

This study analyzes the activity-travel data obtained from the 1990 San Francisco Bay Area activity-travel diary survey conducted for the Metropolitan Transportation Commission (MTC) by E.H. White and Company, Nelson/Nygaard and Phase III Research of Northern California. The survey collected one-weekday activity-travel data for 21,278 individuals in 9,359 sampled households. The sample formation process for non-workers comprised two steps: a) Sample formation and b) Data assembly.

\subsection{Sample Formation}

Of the 21,278 individuals for whom the activity-travel data was collected, 8,112 were not employed. Among these non-workers, approximately half were students. Since the activity-travel behavior of students is usually built around their school schedule, students' activity-travel behavior may be analyzed in a manner similar to that for workers. Hence, in this paper, we focus on the activity-travel behavior of non-workers who are not students. Dropping the full and part time students from the 8,112 non-workers left 4,328 non-student non-workers in the data set (for the sake of presentation simplicity, we will refer to these non-student non-workers simply as non-workers).

Among the 4,328 non-workers, 2,864 individuals pursued at least one out-of-home activity while the remaining 1,464 individuals stayed at home all day. After detailed consistency checks to screen out invalid activity-travel patterns, 2,327 individual records remained from the original 2,864 (81.25\%) individuals who pursued at least one out-of-home activity (see Misra, 1999 for details of the consistency/screening checks). A random sample of 1,190 individuals was then drawn from the 1,464 individuals who stayed at home all day and these individuals were added to the 2,327 screened individual records with at least one out-of-home activity. This procedure ensures that the ratio of individuals with no activity and individuals with one or more 
out-of-home activities in the raw data is maintained in the final sample. The final sample, thus, comprises 3,517 individuals. The descriptive statistics of household and individual characteristics in this final sample are provided in Table 1.

\subsection{Data Assembly}

The trip file corresponding to the travel of the 2,327 individuals who made at least one stop in the final sample was translated to an equivalent activity episode file to obtain details of the activities pursued by individuals. Activity episodes were classified into six purpose types: 1) serve child/ serve-passenger, 2) personal-business/ medical/ dental, 3) shopping, 4)social/ recreation, 5) home-stay, and 6) other activity. We will refer to these six activity types as servepassenger, personal-business, shopping, recreation, home, and other, respectively.

Information on the organization of activity episodes was obtained by determining the number of tours in the day and assigning each activity episode to a particular tour. Sequencing information of activity episodes during the course of the day was retained by recording the activity immediately preceding each episode (except the first episode of the day, i.e., first homestay). The distribution of activity-pairings (i.e., pairs of consecutive activity episodes) was later obtained to study the state dependence effects.

The activity episode file was used to examine the activity-travel behavior of non-workers and obtain information on the three important dimensions constituting their overall activitytravel pattern. The results of the exploratory analysis are organized in the next three sections. 


\section{NUMBER OF STOPS OF EACH ACTIVITY TYPE}

\subsection{General Description}

The first set of attributes that was studied relate to non-workers' propensity to participate in at least one stop of each activity type and the total number of stops undertaken for that activity type.

The distribution of individuals who participated in at least one episode of each activity type, and the mean number of episodes of each type among those who participated in that activity type, is provided in Table 2 . The third column of the table shows that almost half of the non-workers who go out participate in a personal-business activity or a shopping activity at least once during the day. Recreation activity is also pursued relatively frequently at least once in the day. In comparison, relatively few non-workers participate in a serve-passenger activity. However, among those who participate in serve-passenger activity, the average number of stops for this activity type is much higher than the number of stops for other activity types (see last column of Table 2). Further investigation indicates that the percentage of non-workers undertaking two stops for a serve-passenger activity (38.84 percent) is almost the same as the number of individuals undertaking one stop for this activity (39.27 percent). This is not surprising, since many non-workers drop off their kids/others in the morning and pick up these individuals again later in the day. Compared to the participation levels in serve passenger activity, two-thirds of the non-workers who participate in a personal-business activity or a shopping activity pursued such activities only once during the day.

Table 2 also indicates that very few non-workers participate in "other" (i.e., indeterminate) activity types. Of course, each of the 2,327 non-workers who went out have at least one home episode (i.e., a return home trip), as can be observed from the last row of the table. 


\subsection{Effect of Household and Individual Characteristics}

This section explores the effects of a variety of household and individual characteristics on the distribution of the number of stops of each activity. A binary logit formulation is employed to analyze participation in at least one stop for each activity type, followed by an ordered response logit structure to examine number of participations for each type among those participating at least once in that activity type. However, in this paper, we present only the results for the binary logit model of at least a single participation in each activity type (the ordered response logit results indicated little variation across individuals based on their sociodemographics; this is perhaps a result of the fact that most individuals make either one stop or no stops at all of each activity type).

Table 3 presents the four binary logit model estimation results for the propensity of an individual to undertake at least one stop of each of the following four activity types: serve passenger, personal business, shopping, and recreation. Four sets of variables are included: household socio-demographics, household race, household structure, and individual sociodemographics.

Among household socio-demographics, the results indicate that non-workers in households with high income (greater than $80 \mathrm{k}$ per year) are significantly more likely to undertake a recreational activity than non-workers in low-income households (see Bhat, 1998 for a similar result). Individuals in large households participate less in shopping activity, while individuals in households with many children undertake more serve passenger activity (presumably to drop off/pick up children). The presence of other adults in the household enables task sharing and, therefore, appears to reduce participation in serve passenger and personal business activities (as indicated by the effect of the remaining household socio-demographic variables in Table 3). Household location variables were also introduced in our specifications to proxy the effect of locational differences in accessibility to activity opportunities (household location was classified into one of six area types; Central Business District (CBD) core, CBD 
area, urban business, urban, suburban, and rural; based on the population and employment densities of the traffic zone of residence of the household). However, these variables were not statistically significant for any of the activity purposes.

Household race is not observed to have a significant impact on the likelihood of participating in a serve passenger activity; however, in general, non-Caucasians are less likely than Caucasians to participate in any of the other activity types.

The household structure variables are introduced as dummy variables. The base category corresponds to those household structures that do not fall under any of the household structures listed in the table (these excluded household structures are single parent, extended family and other household family types). The results indicate that non-workers in nuclear family households with young children are most likely to pursue serve passenger activity, while retired couples participate more in personal business (this latter result may be, in part, explained by the higher number of medical visits by older individuals). The household structure variables have a particularly significant impact on participation in recreation activity. Specifically, individuals living alone and individuals in couple families have a higher probability of participation in recreation activities than other household types, possibly because of fewer child rearing and household schedule constraints. At the other extreme, individuals who are single parents and individuals in extended joint families are the least likely to participate in recreational activities. This is an interesting finding, since it suggests that single parents may not be finding the time to pursue recreational activity alone and/or with their children.

Within the category of individual socio-demographics, the results show that a) women are observed to have a higher propensity to participate in shopping activity and a lower likelihood of pursuing recreational activity, b) individuals with a driving license have a higher probability to undertake an activity of any type due to their higher mobility, and c) retired individuals participate more in personal business activity (which includes medical visits. These results are similar to those obtained in a number of earlier studies (see Bianco and Lawson, 1996 
and Bhat, 1998). Finally, physically challenged individuals are unlikely to participate in recreational and shopping activities.

To summarize, participation in out-of-home activity type is influenced by a number of household and individual characteristics. At a time when there are substantial changes in sociodemographics, these results have significant implications for mobility and transportation planning (as we discuss in the conclusions section).

\section{ACTIVITy Chaining BEHAVIOR}

This section examines the tendency of non-workers to organize their stops for different activities into tours.

\subsection{General Description}

Analysis of the number of tours undertaken indicates that a little over a third of nonworkers do not go out during the day at all while less than 3 per cent of individuals make more than three tours. The mean value of the number of tours is 1.57 across all non-workers who pursue at least one out-of-home activity.

Among individuals who participate in two or more total stops in the day, the overall average number of stops undertaken in a tour is 2.13 and the standard deviation is 1.15 . This indicates significant activity chaining among non-workers, as well as substantial variations in activity chaining across individuals. However, some of the inter-individual activity chaining variation may be the result of different participation levels in the various activity types rather than due to demographic differences among individuals. To examine (and disentangle) these two effects, we estimate an activity chaining model in the next section. 


\subsection{Effect of Activity Participation and Household/Individual Characteristics}

Table 4 presents the estimation results of a model representing the effect of activity participation characteristics and household/individual attributes on the activity chaining behavior of non-workers. The model has a multiple linear regression structure. The dependent variable represents a measure of activity chaining propensity computed as the total number of stops undertaken by the non-worker divided by the total number of tours into which these stops are organized.

The effect of the activity participation variables indicates that the tendency to chain activities is strongly related to the number of stops undertaken by the individual during the day. This is because individuals participating in many activities are likely to have a more purposeful organization pattern for their activities (see Strathman et al., 1994 for a similar result in the context of worker activity patterns). The effect of number of stops is the most pronounced for shopping stops; that is, shopping stops are most likely to be linked with other stops. As expected, individuals with a high number of serve passenger stops are the least likely to chain activities due to the typical temporal constraints of this activity.

The effects of the household socio-demographic variables suggest a decrease in activity chaining propensity for individuals in households with several vehicles and in households living in an urban area. Since the accessibility to activity participation is usually much higher in urban areas, individuals living in urban areas may not require the level of efficiency in the organization of their out-of-home activities as do non-workers living in non-urban areas.

Household race does not impact activity chaining propensity. Among the household structure and individual socio-demographic variables, retired couples and women have a greater tendency to link activities (see Lockwood and Demetsky, 1994 for a similar result).

To summarize, both activity participation by type and household/individual factors affect activity chaining propensity. This is an important result, since previous studies have seldom accommodated both these effects jointly. Strathman et al. (1994), Bhat (1997), and Lockwood 
and Demetsky (1994) incorporate the effect of total number of non-work stops, but do not distinguish among the differential tendencies to chain based on type of stop. The findings from these earlier studies that activity chaining is affected by a larger set of household/individual factors (than found in our analysis) may be a consequence of not controlling for type of stop. On the other hand, a study by Goulias and Kitamura (1989) accommodates the differential effect of stops by type, but does not include variations in household/individual factors.

\section{ACTIVITy SEQUENCING ANALYSIS}

The activity sequencing analysis is presented under three headings that examine a) activity type of the first and last stops of the day, b) effect of household and individual attributes on activity type of first and last stop of the day, and c) state dependence effects between consecutive activity episodes.

\subsection{Activity Type of First and Last Stops of the Day}

Table 5 provides the overall likelihood of each activity type being undertaken as the first or last stop of the day, conditional on participation in that activity type. The results are presented only for individuals who undertake at least two stops during the day.

The second column in Table 5 shows that serve passenger activity has the highest likelihood (67.2 percent) of being the first stop of the day. The likelihood of participation in a personal business stop as the first stop of the day is also quite high (64.1 percent). A shopping stop is least likely to be undertaken at the beginning of the day.

The third column in Table 5 reveals that individuals are least likely to schedule a personal business activity as the last stop of the day. A number of personal business activities, e.g., medical and dental activities, involve strict temporal constraints and hence are likely to be pursued during the middle of the day. The high likelihood of serve passenger activities being the last stop of the day $(56.6 \%)$, along with the earlier finding that such stops are very likely to be 
the first stop of the day, suggests a drop off/pick-up schedule that temporally "confines" the daily activity patterns of non-workers pursuing serve passenger activities. Finally, the results in Table 5 show that shopping is often pursued as the last stop of the day.

\subsection{Effect of Activity Participation and Household/Individual Characteristics}

Binary choice models are used to analyze the effect of socio-demographic characteristics on the propensity of each activity type being a first (last) stop of the day. The dependent variable in these models takes a value 1 if that particular activity is chosen as the first (last) stop of the

day and 0 otherwise. Hence, eight models corresponding to each combination of four activity types and two terminal stops (first or last stop) are estimated. The models in this section are estimated for individuals who pursued at least two stops in the day.

Table 6 presents the estimation results of the four models representing the effect of socio-demographic characteristics on the activity type of the first stop of the day. The likelihood of an activity being the first stop of the day is associated with the total number of stops of that particular activity type, as one would expect. The household socio-demographic variables indicate that the number of young children and the number of adults play a role in determining the first stop of the day. Specifically, non-workers in households with young children have a high propensity to start their day with a serve passenger activity relative to other activities. On the other hand, non-workers in households with many adults are very likely to start their day with a shopping activity, possibly because responsibility for morning personal business and serve passenger activities can be shared with the other adults. Finally, older individuals have a higher tendency to pursue recreation activities in their first stop, and individuals with a driving license are less likely to participate in shopping activities in the first stop.

Table 7 presents the corresponding results for the last stop of the day. As in the case for the first stop of the day, individuals who make more number of stops of a particular activity type 
are more likely to undertake that stop as the last stop of the day. Household and individual attributes do not play much of a role in influencing the activity type of the last stop of the day.

To summarize, the first and last activity stops of the day are determined primarily by the activity types in which individuals participate. It appears that sequencing of activities is determined by the activities to be pursued, and that there is little systematic variation in activity organization due to household and individual characteristics. In the next section, we examine activity sequencing in more detail within the context of participation in different activity types.

\subsection{State Dependence Effects between Consecutive Activity Episodes}

A study of the state dependence between activity types of consecutive stops provides further information about the sequencing of the different activities performed by a non-worker in his/her daily activity-travel pattern.

Table 8 presents the transition matrix of activity types. Each row corresponds to the activity type of the current stop and each column corresponds to the activity type of the stop (or home return) immediately following the current stop.

Each entry (of current and subsequent activity type) in Table 8 indicates the state dependence between the current row activity and the subsequent column activity, and provides the likelihood that the subsequent activity will occur (in the sample) given the current activity type. We observe that in addition to the high percentages in the next to last column (corresponding to the home-stay activity), the transition matrix exhibits high magnitudes along the diagonal. These results imply that an activity of a particular type is most likely to be followed by a return home or by another activity of the same type.

The "home" column (last column) in the table indicates that across activity types, shopping activity is most likely to be followed by a return home while personal-business activity is least likely to be followed by a return home. This result is quite intuitive, since individuals are likely to return home after performing a shopping activity because of the perishable nature of 
food products (this reinforces the result earlier that shopping tends to be the last activity of the day).

We now proceed to examining the likelihood of occurrence of subsequent activity types other than return home. The first row in Table 8 indicates that if the current activity type is servepassenger, the next most probable activity is another serve-passenger stop if the individual does not immediately return home after performing the activity. The other three activity types personal-business, shopping, and recreation - are all almost equally likely to be undertaken after a serve-passenger stop.

If the current episode activity type is personal-business, then the next episode is most likely to be another personal-business activity or a shopping activity. Serve-passenger and stops for other unclassified purposes are the least likely to occur after a personal-business activity.

If the current activity is shopping, the next activity is also likely to be shopping in 19.2 per cent of the cases. The proportions of other activity types following a shopping activity episode are relatively less. The fact that a significant proportion of other activity types (including recreation activities) are followed by a shopping activity, but a shopping activity episode is predominantly followed by another shopping activity (or a return home), implies that nonworkers tend to organize their tours such that shopping activities occur later on in a tour.

\section{SUMMARY AND CONCLUSIONS}

The activity-based approach has received substantial attention in the past decade. However, much of the current activity-travel literature focuses on studying the characteristics of workers, with relatively little attention being placed on examining non-worker activity-travel patterns. In contrast, non-work trips constitute an increasingly large proportion of urban trips (see Gordon et al., (2)), and non-workers make a significant fraction of such trips. This paper has explored three dimensions characterizing the overall generation and "high-level" organization of activities in the daily activity-travel pattern of non-workers in the San Francisco Bay area. The 
three dimensions are the number of stops of each activity type in the day, activity chaining behavior, and the sequencing of activities. Misra (1999) associates these dimensions with the overall daily activity-travel pattern and refers to them as pattern-level attributes. He indicates that the pattern-level attributes are driven by the basic activity needs of the individual (and the household of which the individual is a part), and therefore may be considered to be at the highest level of the analysis hierarchy for non-workers. On the other hand, decisions regarding stop-level attributes (stop duration, travel time to stop from previous stop, and location of stop) tend to be driven primarily by scheduling convenience, short-term temporal constraints, and travel conditions. Consequently, these attributes are relegated to the lowest level of the analysis hierarchy. Tour-level attributes (travel mode for a tour and the home-stay duration preceding the tour) are positioned at the intermediate level of the analysis hierarchy since these decisions affect all stop-level attributes within the tour.

The exploratory analysis of the pattern-level attributes in this paper highlights several important characteristics in non-worker activity-travel patterns, as discussed below.

\subsection{Number of Stops by Activity Type}

Important summary results from our analysis for this dimension of the non-worker activity travel pattern are as follows: a) Relatively few non-workers participate in a serve passenger activity compared to other activity types, but those who pursue serve passenger activities are likely to undertake multiple stops of this type, b) Individuals living in households with a high number of young children participate in more serve passenger stops, while individuals in households with several old adults participate less in serve passenger stops, c) Caucasians participate in more activity stops outside home than do non-Caucasians, d) Household structure has a significant impact on recreation activity participation; single-parent and extended joint families are least likely to participate in recreational activity and 
couples/single member families most likely to participate in this activity, and e) Locational attributes do not appear to affect stop-making behavior.

The results above have quite substantial implications for transportation and air quality planning because of changing population demographic trends. For instance, projections suggest that households with no kids below 18 years of age will increase from about $53 \%$ today to about $60 \%$ in the next decade (see US Bureau of Census, 1996a). At the same time, the population is aging. According to our analysis of stop-making behavior, these demographic changes imply a reduction in serve passenger stops over time. Similarly, the racial composition of the population is changing rapidly; the US Bureau of Census (1996b) projects a decrease in the Caucasian fraction of the US population from $72 \%$ today to $67 \%$ in 2010 and to $53 \%$ in 2050 . The result, according to our empirical analysis, is a reduction in out-of-home stops made by non-workers. The foregoing effects have positive benefits in terms of congestion alleviation. However, on the negative side, couple families and individuals living alone are on the rise, and "traditional" nuclear family households are on the decline (a recent survey by the University of Chicago indicates that the percentage of nuclear families with young kids decreased from $45 \%$ in 1972 to 26\% in 1998; see Austin American Statesman, 1999). These results imply an increase in recreation activity stops over time. To the extent that recreation stops are much longer in duration than serve passenger stops, the net result of a decrease in serve passenger stops and an increase in recreation stops could be detrimental to air quality since there may be more vehicle starts made in the cold start mode.

From a broader societal standpoint, the analysis results indicate that individuals in single parent households are not very likely to pursue recreational stops (including exercising, walking, playing outdoor games, etc.). This might reflect the substantial time constraints on such individuals. With an increasing fraction of single parent households, population health concerns might warrant the consideration of societal policies that free up time for single parents (such as 
building inexpensive and "round-the-day" mixed recreation/child-care facilities for single parents).

An interesting result in our analysis is that location of the household does not impact stop-making of non-workers. That is, spatial factors of accessibility to activity opportunities do not influence participation in activity stops. This suggests that activity generation is primarily determined by the activity needs of the individual (as part of her/his household), not by the activity environment. Another perspective is that individuals and households locate themselves in areas which provide accessibility to activity opportunities that are compatible with their mobility needs, and this manifests itself in the form of lack of effect of accessibility on stopmaking. Thus, transportation and urban policies aimed at influencing level-of-service or "reach" of activities may not substantially impact activity stop-making.

\subsection{Activity Chaining Behavior}

The results from the activity chaining analysis indicate the following: a) Serve passenger stops are the least likely to be linked with other stops, while shopping stops are most likely to be chained, b) Individuals in households with many vehicles and in households residing in urban areas have a lower activity chaining tendency, c) Race does not impact activity chaining behavior, d) Retired couples are more likely to chain activities, while nuclear family households with kids are unlikely to chain activities, e) Women are more likely to link activities than men..

The results above have important planning implications. As indicated in the previous section, there is likely to be a decrease in serve passenger stops and an increase in recreation stops over time. The consequence, based on our activity chaining analysis, is an increase in linking activities. This would result in travel cost and time efficiencies, and a positive benefit to overall efforts to reduce traffic congestion levels. To the extent that activity linking may result in fewer cold starts (because of a reduction in long home stay duration episodes between activity participations), there would also be air quality improvement implications. However, the 
projected increase in retired couples and decrease in nuclear family households with small kids will result in de-coupling of activities, which implies negative traffic congestion and air quality impacts. Increasing urbanization also has similar negative impacts.

In summary, activity participation behavior and household/individual characteristics have an impact on activity chaining. These complex, and conflicting, impacts will have to be carefully considered in evaluating alternative congestion management and air quality improvement policies.

\subsection{Activity sequencing Behavior and a Proposed Modeling Framework}

The activity sequencing analysis provides the following results: a) Among all activity types, serve passenger stops are most likely to be the first stop of the day (conditional on participation in serve passenger activity) and shopping activities are the least likely to be pursued as the first stop, b) Serve passenger and shopping activities are most likely to be the last stops in a day (conditional on participation in these activities), while personal business stops are least likely to be the last stop, c) Individuals in households with young children tend to begin their day with serve passenger activities, d) Older individuals participate earlier in the day in recreation activities and later in the day in shopping activities, e) an activity of a particular type is most likely to be followed by a return home or by another activity of the same type, and f) Personal business and recreational stops are frequently linked with shopping stops, and are pursued before a shopping stop.

An important result from the sequencing analysis is that there appears to be little systematic variation across individuals in the sequencing of activities. That is, activity sequencing is primarily determined by the type of activities in which an individual participates, and not by variations in individual/household characteristics.

While this paper examines the activity pattern of non-workers, the analysis is of an exploratory nature. In particular, various dimensions of the non-worker activity travel pattern are 
considered independently of other dimensions. Also, the tour level and stop-level attributes have not been examined. A more rigorous and comprehensive analysis methodology would consider jointness in choices in pattern-level attributes as well as include tour/stop level attributes. A possible analysis approach may be to first model activity generation (participation in, and number of stops of, each activity type in an individual's daily pattern), then model overall activity organization (including activity chaining, assignment of stops to tours, and sequencing of activities), and finally analyze tour-level and stop-level attributes.

The activity generation component can be analyzed using a joint binary logit-ordered response structure for participation (binary choice) and number of stops (ordered-response) of each activity type. This model should accommodate sample selection in number of stops based on the participation decision. That is, the number of stops is observed only for those individuals who participate at least once in the activity type. If the same unobserved individual factors influence both the participation decision and the number of stops decision, there is error correlation in these two choices which must be accommodated.

The overall organization component may be modeled using an entire pattern string (beginning at home and ending at home) as the unit of analysis. Conditional on information on activity participation by type, there are several permutations of possible pattern string sequences (a pattern string sequence includes a string of activity stops interspersed with home episodes; the number of intermediate home episodes immediately provides the number of tours). A discrete choice model may be developed for the choice of pattern string from among the various possible permutations. The utility of each permutation can be developed as the sum of a) the utility of number of intermediate home episodes given total stops by type and household/individual attributes, b) the utility of distribution of stops among tours (for example, the utility of making one stop in the first tour and two stops in the second tour as opposed to two stop sin the first tour and one stop in the second tour), and c) the utility of the combination of sub-utilities from activity pairings. Since the number of pattern string alternatives for a given number of activity 
stops by type may be very large, sampling of alternatives can be undertaken in the choice model development.

The tour level attributes; mode choice for tour and home stay duration before tour; may be modeled using traditional discrete choice methods and hazard duration models, respectively. The stop-level attributes (travel time to stop from the previous stop or from home, activity duration of stop, and location of stop) can be modeled using a discrete-continuous econometric system (see Bhat, 1998 for the application of such a system to examine the activity patterns of workers after they arrive home at the evening from work).

\section{ACKNOWLEDGEMENTS}

This research was supported by National Science Foundation Grants DMS 9208758 and DMS 9313013 to the National Institute of Statistical Sciences (NISS). The authors would also like to thank four anonymous referees for comments that considerably improved and strengthened the paper. 


\section{REFERENCES}

Austin American Statesman (1999). Poll: Only a quarter of families are 'traditional', November $26^{\text {th }}$, A31.

Axhausen, K. and T. Gärling (1992). "Activity-based approaches to travel analysis: conceptual frameworks, models and research problems", Transport Reviews, vol. 12, pp. 324-341.

Bhat, C.R. (1997). Work travel mode choice and number of nonwork commute stops, Transportation Research, 31B, 41-54.

Bhat, C.R. (1998e) A post-home arrival model of activity participation behavior, Transportation Research, 32B, 361-371.

Bhat, C. R. and F. S. Koppelman (1999). "A retrospective and prospective survey of time-use research”, Transportation, vol. 26, no. 2, pp. 119-139.

Bhat, C. R. and S. K. Singh (1998). "A comprehensive daily activity-travel generation model system for workers", forthcoming, Transportation Research.

Bianco, Martha J. and Catherine Lawson (1996). "Trip-chaining, childcare and personal safety: critical issues in women's travel behavior", Presented at the Second National Conference on Women's Travel Issues, Baltimore, Maryland, October 24-26, 1996.

E.H. White and Associates (1991). 1990 Bay Area travel survey, Final Report to the San Francisco Bay Area Metropolitan Transportation Corporation, January 1991.

Goulias, K.G. and R. Kitamura (1989). Recursive model system for trip generation and trip chaining, Transportation Research Record, 1236, 59-66.

Jones, P. M., F. S. Koppelman, and J. P. Orfeuil (1990). "Activity analysis: state of the art and future directions", Developments in Dynamic and Activity-Based Approaches to Travel Analysis, pp. 34-55, Gower, Aldershot, England.

Kurani, K. S. and R. Kitamura (1996). Recent developments and the prospects for modeling household activity schedules, Report prepared for the Los Alamos National Laboratory, Institute of Transportation Studies, University of California, Davis, CA.

Lockwood, P.B. and M.J. Demetsky (1994). Nonwork travel - A study of changing behavior", presented at the 73rd Annual Meeting of the Transportation Research Board, Washington, D.C., January.

Mahmassani, Hani S., S. Gregory Hatcher, and Christopher G. Caplice (1997). "Daily variation of trip chaining, scheduling, and path selection behavior of work commuters", in Peter Stopher and Martin Lee-Gosselin (eds.), Understanding Travel Behavior in an Era of Change, Pergamon, Elsevier Science Ltd., Oxford, UK, pp. 351-379. 
Misra, R. (1999). "Toward a comprehensive representation and analysis framework for nonworker activity-travel pattern modeling", Doctoral Dissertation, Department of Civil Engineering, University of Texas, Austin, TX, unpublished.

Strathman, J.G., K.J. Dueker and J.S. Davis (1994). Effects of household structure and selected travel characteristics on trip chaining, Transportation, 21, 23-45.

U.S. Bureau of Census (1996a). Projected Number of Families with Children under 18 Years by Type: 1995 to 2010. Population Division, Population Projections Branch. http://www.census.gov/population/www/projections/nathh.html.

U.S. Bureau of Census (1996b). Resident population of the U.S. by Race, March 1996, www.census.gov/population/projections/nation/nsrh. 
Table 1. Descriptive sample statistics

\begin{tabular}{|c|c|c|}
\hline Variable & Mean & S.D. \\
\hline Household Socio-demographics & & \\
\hline Household size & 2.60 & 1.37 \\
\hline Number of children less than 5 years old & 0.20 & 0.54 \\
\hline Number of children between 5 and 16 years & 0.23 & 0.64 \\
\hline Number of individuals between 22 and 65 years & 1.37 & 1.10 \\
\hline Number of individuals over 65 years & 0.67 & 0.80 \\
\hline Number of workers & 0.58 & 0.76 \\
\hline Number of retired individuals & 0.98 & 0.84 \\
\hline Income (in thousands) & 40.59 & 30.50 \\
\hline Number of vehicles & 1.88 & 1.21 \\
\hline Residence in city core & 0.03 & 0.17 \\
\hline Residence in urban area or urban fringe & 0.23 & 0.42 \\
\hline Residence in suburban area & 0.69 & 0.46 \\
\hline Residence in rural area & 0.06 & 0.23 \\
\hline Household Race & & \\
\hline Caucasian & 0.76 & 0.43 \\
\hline African American & 0.07 & 0.25 \\
\hline Hispanic & 0.07 & 0.25 \\
\hline Asian & 0.09 & 0.28 \\
\hline Other (including Native American) & 0.02 & 0.09 \\
\hline Household Structure & & \\
\hline Non-retired couple & 0.14 & 0.34 \\
\hline Retired couple & 0.23 & 0.42 \\
\hline Nuclear with all children $<22$ years & 0.18 & 0.38 \\
\hline Nuclear with at least one child $>22$ years & 0.05 & 0.22 \\
\hline Single parent & 0.06 & 0.17 \\
\hline Single member & 0.16 & 0.37 \\
\hline Extended family & 0.08 & 0.16 \\
\hline Other (including co-habitation) & 0.10 & 0.04 \\
\hline Individual Socio-demographics & & \\
\hline Age & 57.51 & 17.73 \\
\hline Female & 0.67 & 0.47 \\
\hline Driver & 0.81 & 0.40 \\
\hline Retired & 0.61 & 0.49 \\
\hline Physically challenged & 0.07 & 0.25 \\
\hline
\end{tabular}


Table 2. Number of episodes of each activity type

\begin{tabular}{|c|c|c|c|}
\hline \multirow[t]{2}{*}{ Activity Type } & \multicolumn{3}{|c|}{$\begin{array}{c}\text { Individuals who participated at least } \\
\text { once }\end{array}$} \\
\hline & Frequency & Percent & $\begin{array}{l}\text { Mean \# of } \\
\text { episodes }\end{array}$ \\
\hline Serve Passenger & 466 & 20.00 & 2.08 \\
\hline Personal Business & 1153 & 49.60 & 1.60 \\
\hline Shopping & 1283 & 55.10 & 1.49 \\
\hline Recreation & 997 & 42.80 & 1.41 \\
\hline Other & 220 & 9.50 & 1.34 \\
\hline Home & 2327 & 100.00 & 1.57 \\
\hline
\end{tabular}


Table 3. Effect of socio-demographic variables on the propensity of participation in each activity type

\begin{tabular}{|c|c|c|c|c|c|c|c|c|}
\hline \multirow[t]{2}{*}{ Explanatory Variable } & \multicolumn{2}{|c|}{ Serve Passenger } & \multicolumn{2}{|c|}{ Personal Business } & \multicolumn{2}{|c|}{ Shopping } & \multicolumn{2}{|c|}{ Recreation } \\
\hline & Coefficient & t-statistic & Coefficient & t-statistic & Coefficient & t-statistic & Coefficient & t-statistic \\
\hline Constant & -3.468 & -11.168 & -1.190 & -8.585 & -0.715 & -5.051 & -1.725 & -11.304 \\
\hline $\begin{array}{l}\text { Household Socio-demographics } \\
\text { Income }>80 \mathrm{k} \\
\text { Household Size } \\
\text { Number of children between } 5 \text { and } 16 \text { years } \\
\text { Number of individuals between } 22 \text { and } 65 \text { years } \\
\text { Number of individuals over } 65 \text { years } \\
\text { Number of workers } \\
\text { Number of retired individuals }\end{array}$ & $\begin{array}{r}- \\
- \\
0.680 \\
-0.163 \\
-0.401 \\
- \\
-\end{array}$ & $\begin{array}{r}- \\
- \\
8.565 \\
-1.866 \\
-3.352 \\
- \\
-\end{array}$ & $\begin{array}{r}- \\
- \\
- \\
- \\
- \\
-0.255 \\
-0.454\end{array}$ & $\begin{array}{r}- \\
- \\
- \\
- \\
- \\
-3.741 \\
-3.810\end{array}$ & $\begin{array}{r}- \\
-0.117 \\
- \\
- \\
- \\
- \\
-\end{array}$ & $\begin{array}{r}- \\
-3.801 \\
- \\
- \\
- \\
- \\
-\end{array}$ & $\begin{array}{r}-0.377 \\
- \\
- \\
-\end{array}$ & $\begin{array}{r}-2.038 \\
- \\
- \\
- \\
- \\
- \\
-\end{array}$ \\
\hline $\begin{array}{l}\text { Household Race } \\
\text { (Caucasian is base) } \\
\text { African American } \\
\text { Hispanic } \\
\text { Asian }\end{array}$ & $\begin{array}{l}- \\
- \\
-\end{array}$ & $\begin{array}{l}- \\
- \\
-\end{array}$ & $\begin{array}{r}-0.302 \\
- \\
-0.581\end{array}$ & $\begin{array}{r}-1.841 \\
- \\
-3.406\end{array}$ & $\begin{array}{l}-0.518 \\
-0.260 \\
-0.260\end{array}$ & $\begin{array}{l}-3.184 \\
-2.205 \\
-2.205\end{array}$ & $\begin{array}{r}-0.377 \\
- \\
-\end{array}$ & $\begin{array}{r}-2.038 \\
- \\
-\end{array}$ \\
\hline $\begin{array}{l}\text { Household Structure } \\
\text { Non-retired Couple } \\
\text { Retired Couple } \\
\text { Nuclear with all children }<22 \text { years } \\
\text { Nuclear with at least one child }>22 \text { years } \\
\text { Single member family }\end{array}$ & $\begin{array}{r}- \\
- \\
0.817 \\
- \\
-\end{array}$ & $\begin{array}{r}- \\
- \\
5.713 \\
- \\
-\end{array}$ & $\begin{array}{r}- \\
0.366 \\
- \\
- \\
-\end{array}$ & $\begin{array}{r}- \\
2.602 \\
- \\
- \\
-\end{array}$ & $\begin{array}{l}- \\
- \\
- \\
-\end{array}$ & $\begin{array}{l}- \\
- \\
- \\
-\end{array}$ & $\begin{array}{l}0.486 \\
0.550 \\
0.315 \\
0.442 \\
0.643\end{array}$ & $\begin{array}{l}3.359 \\
4.288 \\
2.278 \\
2.204 \\
4.669\end{array}$ \\
\hline $\begin{array}{l}\text { Individual Socio-demographics } \\
\text { Female } \\
\text { Driver } \\
\text { Retired } \\
\text { Physically challenged }\end{array}$ & $\begin{array}{r}- \\
1.640 \\
- \\
-\end{array}$ & $\begin{array}{r}- \\
6.470 \\
- \\
-\end{array}$ & $\begin{array}{r}- \\
0.802 \\
0.615 \\
-\end{array}$ & $\begin{array}{r}- \\
6.891 \\
3.806 \\
-\end{array}$ & $\begin{array}{r}0.337 \\
0.416 \\
- \\
-0.427\end{array}$ & $\begin{array}{r}4.075 \\
3.884 \\
- \\
-2.629\end{array}$ & $\begin{array}{r}-0.238 \\
0.649 \\
- \\
-0.443\end{array}$ & $\begin{array}{r}-2.692 \\
5.215 \\
- \\
-2.367\end{array}$ \\
\hline $\begin{array}{l}\text { Sample Size } \\
\text { Log-L }\end{array}$ & & $\begin{array}{r}3095 \\
-978.376\end{array}$ & & $\begin{array}{r}3095 \\
-1894.595\end{array}$ & & $\begin{array}{r}3095 \\
-1991.800\end{array}$ & & $\begin{array}{r}3095 \\
-1772.720\end{array}$ \\
\hline
\end{tabular}


Table 4. Effect of activity participation and household/individual characteristics on the number of stops per tour

\begin{tabular}{|l|r|r|}
\hline \multicolumn{1}{|c|}{ Explanatory Variable } & \multicolumn{2}{c|}{ All Stops } \\
\cline { 2 - 3 } & Coefficient & t-statistic \\
\hline Constant & 0.710 & 7.146 \\
\hline Activity Participation Characteristics & & \\
Number of Serve Passenger Stops & 0.304 & 10.282 \\
Number of Personal Business Stops & 0.468 & 17.965 \\
Number of Shopping Stops & 0.516 & 17.831 \\
Number of Recreation Stops & 0.453 & 14.245 \\
& & \\
\hline Household Socio-demographics & & \\
Number of vehicles & -0.071 & -2.992 \\
Residence in urban area & -0.106 & -1.554 \\
& & \\
\hline Household Structure & & \\
Retired Couple & -0.170 & 2.607 \\
Nuclear with all children <22 years & & -2.888 \\
& & \\
\hline Individual Socio-demographics & 0.125 & 2.081 \\
Female & \multicolumn{2}{|c|}{1316} \\
\hline Sample Size & & \\
Adjusted R Square & & \\
\hline
\end{tabular}


Table 5. Percentage of individuals participating in each activity type who had that activity type as the first or last stop of the day

\begin{tabular}{|l|c|c|}
\hline \multicolumn{1}{|c|}{ Activity Type } & $\begin{array}{c}\text { First Stop } \\
\text { (percentage) }\end{array}$ & $\begin{array}{c}\text { Last Stop } \\
\text { (percentage) }\end{array}$ \\
\hline Serve Passenger & 67.20 & 56.60 \\
Personal Business & 64.10 & 35.60 \\
Shopping & 34.00 & 57.90 \\
Recreation & 42.80 & 52.10 \\
\hline
\end{tabular}


Table 6. Effect of socio-demographic variables on the activity type of the first stop of the day

\begin{tabular}{|c|c|c|c|c|c|c|c|c|}
\hline \multirow[t]{2}{*}{ Explanatory Variable } & \multicolumn{2}{|c|}{ Serve Passenger } & \multicolumn{2}{|c|}{ Personal Business } & \multicolumn{2}{|c|}{ Shopping } & \multicolumn{2}{|c|}{ Recreation } \\
\hline & Coefficient & t-statistic & Coefficient & t-statistic & Coefficient & t-statistic & Coefficient & t-statistic \\
\hline Constant & -3.813 & -19.319 & -2.116 & -17.099 & -2.530 & -7.827 & -3.404 & -18.480 \\
\hline $\begin{array}{l}\text { Activity Participation Characteristics } \\
\text { Number of stops of current activity type }\end{array}$ & 2.354 & 16.839 & 1.720 & 17.118 & 1.255 & 14.185 & 1.868 & 16.318 \\
\hline $\begin{array}{l}\text { Household Socio-demographics } \\
\text { Number of children between } 5 \text { and } 11 \text { years } \\
\text { Number of individuals over } 22 \text { years }\end{array}$ & $\begin{array}{r}0.559 \\
-\end{array}$ & $\begin{array}{r}2.815 \\
-\end{array}$ & $\begin{array}{r}-0.657 \\
-\end{array}$ & $\begin{array}{r}-3.734 \\
-\end{array}$ & $\begin{array}{r}-0.535 \\
0.305\end{array}$ & $\begin{array}{r}-2.454 \\
2.811\end{array}$ & $\begin{array}{l}- \\
-\end{array}$ & $\begin{array}{l}- \\
-\end{array}$ \\
\hline $\begin{array}{l}\text { Individual Socio-demographics } \\
\text { Age over } 65 \text { years } \\
\text { Driver }\end{array}$ & $\begin{array}{l}- \\
-\end{array}$ & - & $\begin{array}{l}- \\
-\end{array}$ & - & $\begin{array}{r}- \\
-0.998\end{array}$ & -4.176 & $\begin{array}{r}0.514 \\
-\end{array}$ & $\begin{array}{r}3.042 \\
-\end{array}$ \\
\hline $\begin{array}{l}\text { Sample Size } \\
\text { Log-L }\end{array}$ & & $\begin{array}{r}1316 \\
-253.725\end{array}$ & & $\begin{array}{r}1316 \\
-593.724\end{array}$ & & $\begin{array}{r}1316 \\
-530.136\end{array}$ & & $\begin{array}{r}1316 \\
-463.790\end{array}$ \\
\hline
\end{tabular}


Table 7. Effect of socio-demographic variables on the activity type of the last stop of the day

\begin{tabular}{|c|c|c|c|c|c|c|c|c|}
\hline \multirow[t]{2}{*}{ Explanatory Variable } & \multicolumn{2}{|c|}{ Serve Passenger } & \multicolumn{2}{|c|}{ Personal Business } & \multicolumn{2}{|c|}{ Shopping } & \multicolumn{2}{|c|}{ Recreation } \\
\hline & Coefficient & t-statistic & Coefficient & t-statistic & Coefficient & t-statistic & Coefficient & t-statistic \\
\hline Constant & -3.767 & -19.358 & -2.761 & -20.402 & -2.242 & -16.439 & -2.533 & -19.137 \\
\hline $\begin{array}{l}\text { Activity Participation Characteristics } \\
\text { Number of stops of current activity type }\end{array}$ & 2.060 & 16.538 & 1.142 & 14.982 & 1.424 & 16.261 & 1.726 & 16.539 \\
\hline $\begin{array}{l}\text { Household Structure } \\
\text { Single member family }\end{array}$ & - & - & - & - & - & - & -0.485 & -2.284 \\
\hline $\begin{array}{l}\text { Individual Socio-demographics } \\
\text { Age over } 65 \text { years }\end{array}$ & - & - & - & - & 0.380 & 2.792 & - & - \\
\hline $\begin{array}{l}\text { Sample Size } \\
\text { Log-L }\end{array}$ & & $\begin{array}{r}1316 \\
-269.709 \\
\end{array}$ & & $\begin{array}{r}1316 \\
-532.797 \\
\end{array}$ & & $\begin{array}{r}1316 \\
-662.293 \\
\end{array}$ & & $\begin{array}{r}1316 \\
-544.606 \\
\end{array}$ \\
\hline
\end{tabular}


Table 8. Transition matrix of activity types

\begin{tabular}{|c|c|c|c|c|c|c|c|}
\hline \multirow{2}{*}{$\begin{array}{c}\text { Current Activity } \\
\text { Type }\end{array}$} & \multicolumn{7}{|c|}{ Subsequent Activity Type } \\
\hline & $\begin{array}{c}\text { Serve- } \\
\text { Passenger }\end{array}$ & $\begin{array}{l}\text { Personal- } \\
\text { Business }\end{array}$ & Shopping & Recreation & Other & Home & Total \\
\hline Serve-Passenger & $15.1 \%$ & $8.1 \%$ & $9.1 \%$ & $8.4 \%$ & $2.0 \%$ & $57.3 \%$ & $100.0 \%$ \\
\hline Personal-Business & $3.4 \%$ & $19.7 \%$ & $18.9 \%$ & $8.7 \%$ & $1.1 \%$ & $48.2 \%$ & $100.0 \%$ \\
\hline Shopping & $3.0 \%$ & $6.8 \%$ & $19.2 \%$ & $5.3 \%$ & $0.7 \%$ & $64.9 \%$ & $100.0 \%$ \\
\hline Recreation & $5.7 \%$ & $8.8 \%$ & $12.4 \%$ & $13.6 \%$ & $1.1 \%$ & $58.5 \%$ & $100.0 \%$ \\
\hline Other & $6.8 \%$ & $10.2 \%$ & $9.5 \%$ & $10.5 \%$ & $10.8 \%$ & $52.2 \%$ & $100.0 \%$ \\
\hline Total & $5.7 \%$ & $11.3 \%$ & $15.6 \%$ & $8.8 \%$ & $1.6 \%$ & $57.0 \%$ & $100.0 \%$ \\
\hline
\end{tabular}

